\title{
SínDROME DE SOTOS: UM ESTUDO DE CASO
}

Juliana Alves Cunha* Valter Cury Rodrigues** Elaine Leonezi Guimarães**

\section{Introdução}

A Síndrome de Sotos, descrita no Uruguai em 1964, é uma desordem genética rara que se caracteriza pelo crescimento físico excessivo durante os primeiros anos de vida, acompanhado de retardo mental moderado, atraso na coordenação motora, hipotonia e deterioração da fala (Guarido, D'Avilla, 2003; Gorlin et al., 2001).

Crianças com essa síndrome tendem a ser grandes ao nascer, mas com o desenvolvimento tornam-se mais altas, mais pesadas e apresentam macrocefalia (Geller, Filho, 2003). Esta síndrome é de ocorrência global, não tendo relação com grupos étnicos. É de baixa incidência, prevalecendo nos indivíduos de sexo masculino (Melo et al., 2002).

A etiologia é pouco conhecida, sendo a maioria dos casos portadores de mutações genéticas (Gorlin et al., 2001; Jones, 1998a). Entretanto, deve-se considerar o risco de transmissão, embora seja relatado como uma condição esporádica, sendo observado como um traço dominante, incluindo transmissão de homem para homem. A herança recessiva foi descrita em gêmeos monozigóticos e primos de primeiro grau (Melo et al., 2002). Contudo, fica difícil averiguar se todos os casos têm uma etiologia comum (Melo et al., 2002; Jones, 1998a).

Sotos e colaboradores, ao descreverem a síndrome, verificaram que as crianças comprometidas apresentavam diversas características como: incoordenação, hipotonia, discreta hiperreflexia e deficiência mental variável, com uma média de coeficiente de inteligência (QI) de 72 (Melo et al., 2002). Alguns

\footnotetext{
* Fisioterapeuta formada pelo Departamento de Ciências Exatas e Naturais (CEN). Centro Universitário de Araraquara - UNIARA.

** Médico Geneticista. Médico responsável pela Clínica Integrada do Centro Universitário de Araraquara - UNIARA. Docente do Curso de Odontologia - UNESP - Araraquara/SP

*** Fisioterapeuta. Mestre em Fisioterapia pela UFSCar. Docente do Curso de Fisioterapia da UNIARA - Araraquara/SP e das Faculdades Integradas Fafibe - Bebedouro/SP.
}

portadores desta síndrome podem apresentar distúrbios comportamentais importantes e anormalidades cardíacas congênitas (Kurotaki et al., 2003; Jones, 1998b).

O retardo mental, a hipotonia e a altura excessiva são os problemas mais importantes. Não há diferença do retardo mental das crianças com síndrome de Sotos das crianças com deficiência mental (Melo et al., 2002). Uma das características principais da doença é o crescimento excessivo tanto pré como pós-natal, sendo comum, ao nascimento, verificar que a estatura aumenta mais que o peso e, durante a infância, há uma maturação óssea avançada (Alhumaidi, 2003). Com o decorrer da idade, pode haver redução da hipotonia e melhora na coordenação motora fina (Melo et al., 2002; Jones, 1998a).

Como características craniofaciais, podem ser observadas: macrocefalia; dilatação discreta dos ventrículos cerebrais; fronte proeminente; fissuras palpebrais oblíquas direcionadas para baixo; hipertelorismo aparente, nem sempre confirmado pela mensuração; mandíbula proeminente; palato alto e estreito com cristas palatinas laterais proeminentes, vermelhidão facial freqüentemente no nariz, nas bochechas e região perioral e também apresenta erupção prematura dos dentes. Podem-se observar também alguns distúrbios ortopédicos como pé plano e o geno valgo, unhas das mãos quebradiças e finas (Jones, 1998a; Jones, 1998b). Os cromossomos geralmente são normais, podendo ocorrer anormalidades ocasionais como convulsões, anormalidades no EEG, estrabismo, anormalidades cardíacas, cifoescoliose, teste de tolerância à glicose anormal, processos malignos, principalmente o Tumor de Wilms (Melo et al., 2002; Gorlin et al., 2001).

O diagnóstico pode ser baseado nos dados clínicos e achado na neuroimagem, e o diagnóstico diferencial pode ser feito principalmente com as síndromes: de Weaver, Bannayan-Riley-Ruvalcaba e XYY (Gorlin et al., 2001). $\mathrm{Na}$ síndrome de Weaver os pacientes apresentam retardo mental e crescimento excessivo. Já na síndrome Bannayan-Riley-Ruvalcaba há presença de macrocefalia, lipomas e hemangiomas, com peso e estatura altos no nascimento (Geller, Filho, 2003; Jones, 1998a). E na síndrome XYY, que geralmente acomete homens, associa-se a um crescimento acelerado na infância e comportamento agressivo (Jones, 1998a; Gardalho, 2003; Tasso, 2003).

Segundo Guarido e D'Avilla (2003), os indivíduos portadores da síndrome são férteis e não há relatos de que a vida é encurtada. A fisioterapia e a prática do movimento podem ser de grande utilidade para o aumento do equilíbrio, aprimoramento das habilidades motoras, da marcha e da postura. A psicologia pode ajudar trazendo beneficios a partir de conselhos envolvendo os problemas comportamentais e sociais durante a infância e a imaturidade em adultos. São recomendadas terapias de fala para o desenvolvimento da linguagem (Melo et al., 2002).

Considerando o escasso número de casos descritos na literatura, buscouse relatar um caso acompanhado na Clínica de Fisioterapia da Uniara, verificando 
a importância de observarem-se as características neuromotoras e cognitivas, e a resposta ao tratamento fisioterapêutico, com a finalidade de compreenderse o diagnóstico e facilitar a intervenção precoce.

\section{Caso}

Criança com 10 anos, sexo masculino, nascido com 3500 gramas, 34 semanas gestacionais, $51 \mathrm{~cm}$ de altura, sendo filho único de mãe primigesta Aos 4 meses de idade, o médico-pediatra notou que apresentava hipotonia significativa, não conseguindo sustentar a cabeça, e convulsões diariamente (durante segundos) (Figura 1). Nesta mesma época, foi dado o diagnóstico médico de síndrome de Sotos. Durante a coleta dos dados, feita a partir do prontuário, pôde-se constatar que o paciente sentou aos 9 meses, não engatinhou, iniciando a marcha com 2 anos e 4 meses (Figura 2). Não há relato familiar de síndrome de Sotos ou de outras patologias neurológicas ou genéticas.

Na primeira avaliação fisioterapêutica realizada na Clínica de Fisioterapia da Uniara, foram observados: hipotonia, discreta hiperreflexia, dismetria e incoordenação motora, marcha independente, porém instável, com base alargada e déficit de equilíbrio, postura dos pés em eversão, joelhos valgos com discreta semiflexão bilateral. A alteração observada na marcha pode estar relacionada ao déficit proprioceptivo e de equilíbrio (Figura. 3, 4, 5). Na última avaliação fisioterapêutica realizada após 11 meses de tratamento, observou-se discreta redução da hipotonia, da hiperreflexia, da dismetria e incoordenação motora, apresentando maior estabilidade na marcha, porém, com discreto déficit de equilíbrio, postura dos pés em eversão e joelhos valgos. Com relação às crises convulsivas, foi relatado pela mãe que estas estavam controladas, há 4 anos. E as demais deficiências como atraso cognitivo, comportamento agitado, comprometimento da fala e estrabismo discreto, permaneceram sendo relatadas pela mãe e observadas durante o tratamento cinesiológico funcional. A criança além do acompanhamento na Clínica de Fisioterapia, teve acompanhamento fonoaudiológico, freqüentou escola, natação e participou de grupo de teatro

Durante o acompanhamento fisioterapêutico, foi utilizado como protocolo de tratamento: alongamentos musculares, treino de dissociação de cinturas, descarga de peso em membros superiores (MMSS) e inferiores (MMII), treino de equilíbrio, treino de marcha, treino de coordenação motora de MMSS, sendo realizado tanto em solo quanto associado à hidroterapia.

Durante os primeiros 3 meses de intervenção fisioterapêutica foi evidenciado que o paciente era incapaz de coordenar os jogos de encaixe, como por exemplo, não realizava o encaixe dos objetos nos respectivos lugares. Durante a marcha apresentava a perda do equilíbrio, resultando em quedas constantes Transcorridos os 11 meses, foi possível observar a importância da prática do movimento, considerando a evolução da criança, principalmente na coordenação motora, onde a mesma passou a realizar a tarefa de encaixar objetos durante a terapia. Verificou-se melhor equilíbrio estático, com o paciente conseguindo se manter por mais tempo sobre uma prancha de equilíbrio com menos apoio. E no equilíbrio dinâmico, a mãe relatou diminuição na freqüência de quedas durante a marcha, sendo observado, durante a terapia, maior equilíbrio ao subir e descer escadas e ao correr ultrapassando obstáculos.

Figura 1. Criança com 3 meses de idade, apresentando fissuras palpebrais oblíquas direcionadas para baixo, hipertelorismo, vermelhidão facial, região frontal proeminente e pé plano.

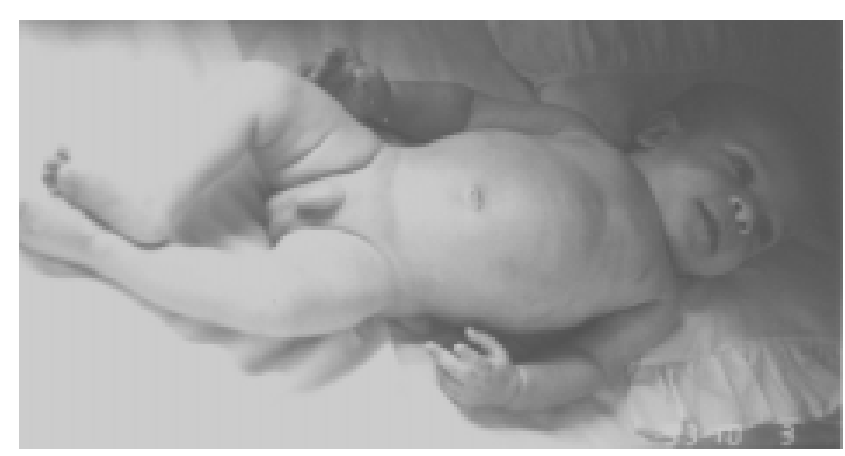

Figura 2 Criança com 2 anos de idade apresentando marcha instável com base alargada.

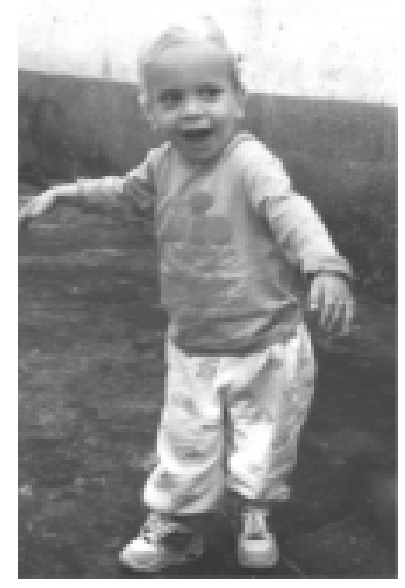


Figura 3. Criança com 10 anos e 2 meses, apresentando escápulas aladas, base alargada e crescimento excessivo de MMSS.

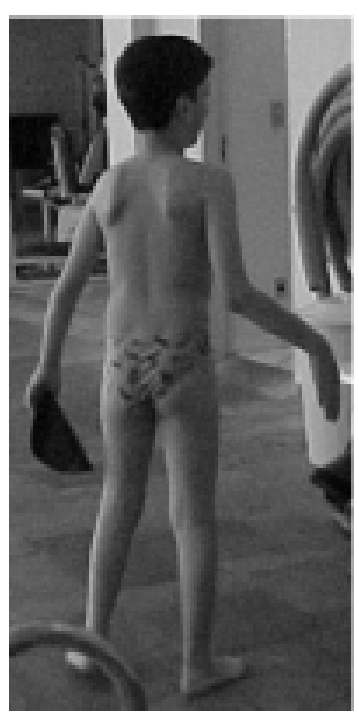

Figura 4. Criança com 10 anos e 2 meses de idade, mostrando marcha com base alargada e joelhos valgo.

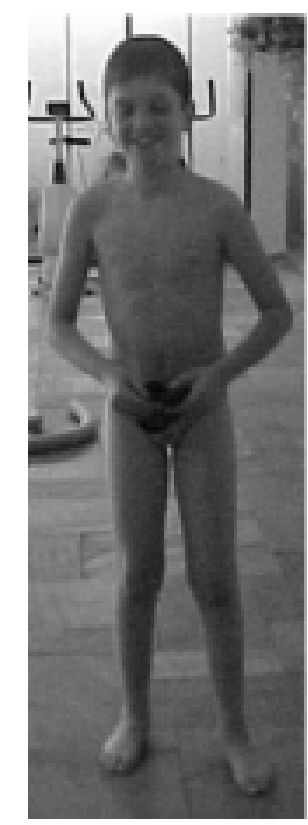

Figura 5. Criança com 10 anos e 2 meses de idade. Pode-se observar presença de hipertelorismo, estrabismo, vermelhidão facial e região frontal proeminente.

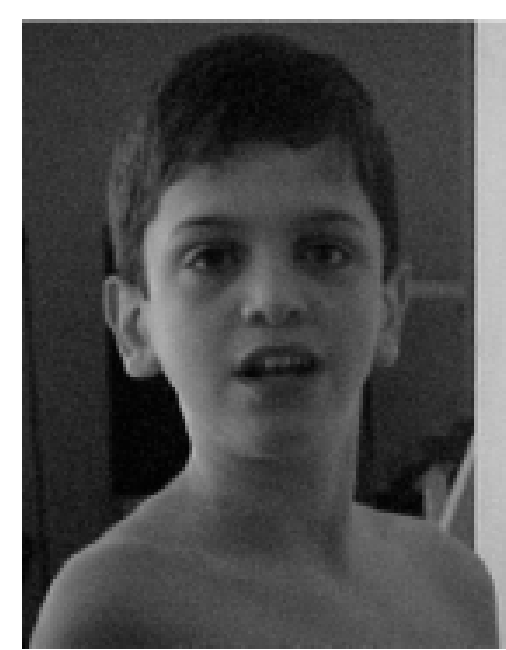

\section{Discussão e conclusão}

De acordo com os achados descritos por Guarido e D'Avila (2003), Gorlin et al., 2001, Geller e Filho (2003), Melo et al. (2002), Jones (1998a), Kutarotaki et al., (2003), Jones (1998b), os resultados dos exames clínicos e complementares do caso relatado justificam o diagnóstico clínico de Síndrome de Sotos.

Considerando as incapacidades da criança durante os primeiros três meses de intervenção fisioterapêutica, e os avanços da criança após onze meses do início do tratamento fisioterapêutico, pode-se acreditar na importância da intervenção. Foi evidente a evolução da criança, principalmente na coordenação motora, onde se observou nos jogos de encaixe a realização da tarefa sem grandes dificuldades; e no equilíbrio, havendo redução de quedas durante a marcha, o que pode estar relacionado ao déficit proprioceptivo e de equilíbrio, melhorado com os exercícios durante o período de intervenção, corroborando com Melo et al., (2002).

Em relação às outras deficiências associadas, foi relatado pela mãe que a criança teve acompanhamento multidisciplinar (fonoaudiologia, psicologia e pedagogia) e que, apesar de apresentar considerável dificuldade na fala, podese observar uma melhor compreensão e um melhor controle do comportamento, corroborando com os achados de Melo et al. (2002), o que facilitou a realização do tratamento fisioterapêutico sem a presença materna. Contudo, a criança mantinha postura inquieta, possessiva e bastante dependente emocionalmente da mãe. 
Embora haja pouca descrição sobre a patologia, etiologia e, principalmente, sobre a importância da intervenção fisioterapêutica nas alterações, observouse sensível evolução da criança durante o tratamento, corroborando os dados da literatura, quando esta relata a importância do movimento na aquisição de habilidades motoras e de postura, e da atuação psicológica no desenvolvimento social, comportamental e de linguagem. (Melo et al., 2002)

Espera-se com este estudo, além de relatar as características apresentadas na síndrome e a importância da intervenção fisioterapêutica e multidisciplinar na evolução e desenvolvimento da criança, contribuir para o enriquecimento do acervo literário.

\section{Referências bibliográficas:}

ALHUMAIDI, M.M.D. Sotos Syndrome: A case report. Disponível em: wwwkfshrc.edu.as. Acesso em: 28 mar. 2003.

GARDALHO, E. Biologia - aberrações cromossômicas numéricas. Disponível em: www.assis.unesp.br. Acesso em: 28 mar. 2003.

GELLER, M.; FILHO, A.B. Neurofibromatose. Disponível em www.cnnf.org.br. Acesso em: 28 mar. 2003.

GORLIN, R.J.; COHEN, M.M.; HENNEKAM, R.C.M. Syndromes of the Head and Neck. 4.ed. New York: Oxford University Press, 2001.

GUARIDO, R.L.; D'AVILLA, V.R.C. Relato do acompanhamento de uma criança com diagnóstico precoce de Síndrome de Sotos durante a fase pré-escolar em uma creche da USP. Disponível em:

www.brazilpednews.org.br. Acesso em: 26 mar 2003.

JONES, K.L. Padrões reconhecíveis de malformações congênitas. 5.ed. São Paulo: Manole, 1998.

Smith's recognizable patherns of human malformation. 4.ed.,

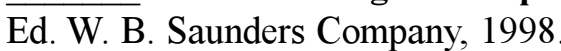

KUROTAKI, N.; HARADA, N.; NIIKAWA, N.; MATSUMOTO, N. Syndrome is case by haploinsufficiency of the NSD1 gene. Disponível em: www.faseb.org. Acesso em: 20 mar. 2003.
MELO, D.G.; ACOSTA, A.X., SALLES; M.A. de A. et al. Síndrome de Sotos (gigantismo cerebral): análise de 8 casos. Arq. Neuro-Psiquiatr. jun. 2002, v.60, n.2A, p.234-238. Disponível em: www.scielo.br. Acesso em: 10 maio 2003

TASSO, E. Genética - aberrações cromossômicas. Disponível em: www.virtual.epm.br. Acesso em: 28 mar. 2003.

\section{Resumo:}

Este estudo destina-se a apresentar um caso de Síndrome de Sotos. Buscou-se relatar a resposta desta criança ao tratamento cinesiológico funcional, considerando as principais características como deficiência mental, hipotonia, distúrbios ortopédicos, estatura elevada, macrocefalia, incoordenação motora e déficit de marcha. Após 11 meses de acompanhamento, observou-se, com o tratamento cinesiológico funcional, melhora do equilíbrio, das habilidades motoras (coordenação), da marcha e da postura. Espera-se com este trabalho, além de apresentar as características da síndrome de Sotos juntamente com seu diagnóstico diferencial, relatar a importância da intervenção fisioterapêutica e do trabalho multidisciplinar envolvendo a psicologia e a fonoaudiologia.

\section{Palavras-chave:}

Síndrome de Sotos; Retardo Mental; Hipotonia; Alterações da Fala; Fisioterapia; Intervenção Multidisciplinar. 